\title{
A RISK MANAGEMENT APPROACH TO EMERGING MARKET'S SOVEREIGN DEBT SUSTAINABILITY WITH AN APPLICATION TO BRAZILIAN DATA
}

\author{
Márcio Garcia \\ Roberto Rigobon \\ Working Paper 10336 \\ http://www.nber.org/papers/w10336
NATIONAL BUREAU OF ECONOMIC RESEARCH
1050 Massachusetts Avenue
Cambridge, MA 02138
March 2004

The views expressed herein are those of the authors and not necessarily those of the National Bureau of Economic Research.

(C)2004 by Márcio Garcia and Roberto Rigobon. All rights reserved. Short sections of text, not to exceed two paragraphs, may be quoted without explicit permission provided that full credit, including (C) notice, is given to the source. 
A Risk Management Approach to Emerging Market's Sovereign Debt Sustainability with an Application to Brazilian Data

Márcio Garcia and Roberto Rigobon

NBER Working Paper No. 10336

March 2004

JEL No. F3

\begin{abstract}
In this paper we study the question of debt sustainability from a risk management perspective. The debt accumulation equation for any country involves variables that are stochastic and closely intertwined. When these aspects are taken into consideration the notion of debt sustainability is expanded to studying the stochastic properties of the debt dynamics. We illustrate the methodology by studying the Brazilian case. We find that even though the debt could be sustainable in the absence of risk, there are paths in which it is clearly unsustainable. Furthermore, we show that properties of the debt dynamics are closely related to the spreads on sovereign dollar denominated debt.

\author{
Marcio Garcia \\ Department of Economics \\ Pontifical Catholic University \\ Rua Marques de Sao Vicente, 225 \\ Gavea - Rio de Janeiro - RJ \\ 22451-041 Brasil \\ mgarcia@econ.puc.rio.br \\ Roberto Rigobon \\ Sloan School of Management \\ MIT, E52-431 \\ 50 Memorial Drive \\ Cambridge, MA 02142-1347 \\ and NBER \\ rigobon@mit.edu
}




\section{Introduction}

There are several ways to assess debt sustainability. A widely used criterion is the gap between the actual primary budget deficit and the one required to keep the debt GDP ratio stable (the "debt stabilizing primary balance"). ${ }^{1}$ This measure has several drawbacks: since the purpose of having debt in the first place is to smooth consumption, why would a country want to keep the debt to GDP ratio constant? Or, if a country is excessively heavily indebted, to keep the debt to GDP ratio would not be sustainable.

Other measures have been proposed. IMF (2003) estimates the fiscal reaction function. The idea is similar to estimate the coefficient of the expected inflation in a Taylor rule, and check whether it exceeds one, as required for the rule to provide a stationary inflation. In the fiscal reaction function, the aim is to estimate how the primary balance reacts to increases in the debt to GDP ratio. Another measure is to compute a ratio between the actual debt level and a benchmark level equal to the present value of future primary surpluses computed under conservative assumptions. If the ratio exceeds one, the country would be over borrowing (IMF 2003).

Risk based measures of fiscal sustainability have been borrowed from the financial literature. One of them is the very famous Value-at-Risk (V@R). Other sustainability measures include stress testing through Monte Carlo simulations. ${ }^{2}$

Here we propose a related measure that takes very seriously the realization that the debt accumulation equation for any country involves variables that are stochastic and closely intertwined. By taking these aspects into consideration, the notion of debt sustainability is expanded to studying the stochastic properties of the debt dynamics. We propose a VAR (Vector Auto Regression) to estimate the correlation pattern of the macro variables and use it to implement Monte Carlo simulations. These simulations allow us to compute "risk probabilities", i.e., probabilities that the simulated Debt to GDP ratio exceeds a given threshold deemed risky (say, $75 \%$ of GDP). ${ }^{3}$ The time-series of such probabilities is then used to investigate whether or not it is correlated with the market risk assessment, measured by the spread on sovereign dollar denominated debt. The application of our methodology for Brazil shows that even though the debt could be sustainable in the absence of risk, there are paths in which it is clearly unsustainable. Furthermore, we show that properties of the debt dynamics are closely related to the EMBI+ Brazil spread.

Next Section describes the data used and performs a few debt decomposition exercises. Section III presents the core methodology and the application to Brazilian data. Section IV concludes.

See IMF (2003), p. 124, for references.

Garcia (2002) computes a V@R for the Brazilian debt and performs Monte Carlo simulations to implement a CF@R (cash-flow at risk).

3 For a financial institution, this probability would be analogous to the probability of wiping out the net worth. 


\section{Brazilian Sovereign Debt}

\section{A. Data Description}

The simulation of the debt dynamics requires the compatibility of many statistics that are produced in different places. Bevilaqua and Garcia (2002) performed a decomposition exercise of the growth sources of the domestic bonded debt in Brazil. The domestic bonded debt is the component of the net public debt that grew the most: from $11.81 \%$ of GDP in December, 1994 to $48.95 \%$ of GDP in September, 2003. Here, we use a similar framework to decompose the sources of growth of the Brazilian net debt.

To put together the data was not a straightforward task, and it took us a few months and many interactions with the Brazilian Central staff to clean the data and adapt them to the format required in the simulations. ${ }^{4}$ Currently, these data are all available at the Brazilian Central Bank web page (www.bcb.gov.br).

We now briefly describe the data. We use debt stocks (domestic, foreign; gross and net) monthly series. These stocks are converted to ratios of GDP using the "valorized" GDP, which are used to compute all ratios of GDP that we use in this paper. The PSBR (public sector borrowing requirements) are computed in three different concepts: primary, operational and nominal. We favor the use of the operational and primary concepts, which mitigate the effects of high inflation, because our sample contains the immediate aftermath of the Real plan, when the inflation came down from almost 50\% per month. Massive distortions (see Figure 2 A) show up in the nominal deficit figures immediately succeeding the Real plan starting point (July 1, 1994) because we use twelve-monthmoving averages to provide comparability and avoid excessive fluctuation. ${ }^{6}$ With the moving averages, until a full year had elapsed, the distortionary effects of the hyperinflation still contaminated the nominal deficit figures. ${ }^{7}$

Two main adjustments have to be taken into consideration in order to make the debt statistics compatible with the PSBR's. First, privatization revenues have the (accounting) effect of reducing the debt, but are not computed as fiscal revenues for purposes of calculating the PSBR. Second, many expenditures incurred in the present are results of

\footnotetext{
$4 \quad$ Box 3.1 (Data on Public Debt in Emerging Market Economies) of the last World Economic Outlook (IMF 2003) describes the many difficulties involved in gathering such data.

5 The "valorized" GDP is a better measure than the nominal GDP because, even under moderate inflation, the simple addition of the GDP flow within a twelve-month period distorts the statistic. For example, for a $10 \%$ yearly inflation, each unit of domestic currency of the last month will be worth 1.1 units of domestic currency of the first month included in the sample. The "valorization" procedure mitigates this distortion. Under zero inflation, the "valorization" procedure reverts to usual addition of monthly GDP flows. Box 3.1 of the World Economic Outlook (IMF 2003) comments on the effects of such procedure, grossly exaggerating them.

Since the deficits are so important to determine debt sustainability, we opted to use twelve-monthmoving averages instead of monthly figures. This is because the latter series is very volatile, often changing signs. For example, if some expenses were concentrated in a given month, the monthly series would show a large deficit among many surpluses, while the moving average would better reflect the fiscal stance.

7 See Figure 2.
} 
previous contingent liabilities that eventually materialized. These "skeletons" have the (accounting) effect of increasing the debt, but are not computed as fiscal outlays for purposes of calculating the PSBR. ${ }^{8}$

The remaining data used are standard. Inflation is measured through the CPI (IPCA) and WPI (IGP-M) indices. Domestic interest rates are measured by the Selic rate. ${ }^{9}$ The country risk is measured through the EMBI and EMBI + Brazil indices produced by JP Morgan. Exchange rates are the month-end PTAX.

\section{B. Decomposition of debt shocks}

Figure 1 displays the evolution of the net debt to GDP ratio since 1994. A few months after the start of the Real Plan, the net debt to GDP ratio started to grow almost monotonically from the $30 \%$ level, reaching levels above $60 \%$ during the 2002 financial and political crisis, and currently hovering around $58 \%$. This very fast growth is deemed the most important fragility in Brazilian macroeconomic indicators. To be sure, although some contend that the level of the net debt could be high given investors collective behavior, ${ }^{10}$ the net debt to GDP ratio in Brazil is not particularly high among nations. The total (probably gross) debt averages $70 \%$ of GDP for emerging market economies (IMF 2003 , p. 116). However, the speed it increased (doubled from $30 \%$ to $60 \%$ in eight years), i.e., the "debt velocity", is unambiguously very concerning.

固

\section{FIGURE 1}

\section{BRAZILIAN PUBLIC NET DEBT (\% of GDP)}

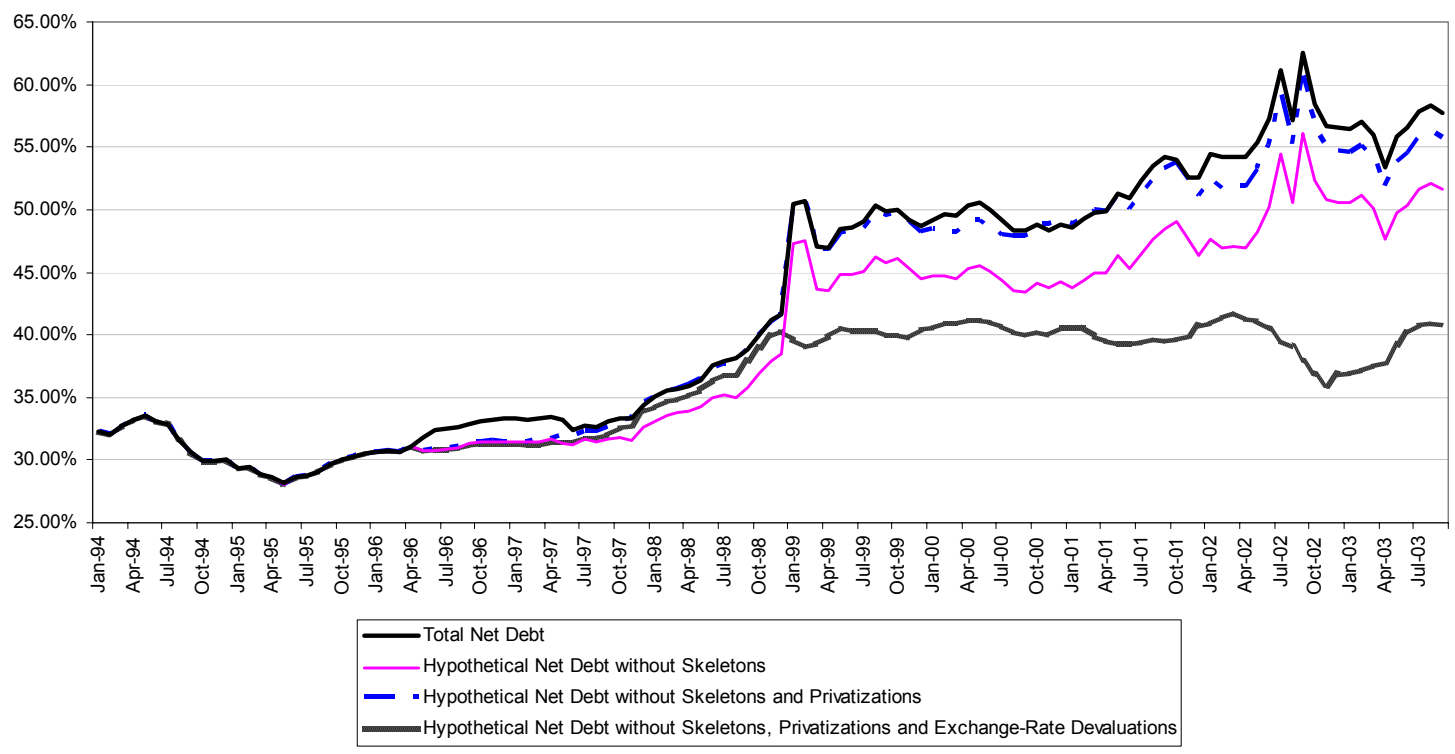

$8 \quad$ Other minor adjustments have to be performed in order to make the debts statistics compatible with the PSBR's, as explained in Bevilaqua and Garcia (2001).

9 The equivalent of the US Fed funds rate.

10 For the "debt intolerance" phenomenon, see Reinhart, Rogoff and Savastano (2003) and IMF (2003). 
The fiscal situation that generated such tremendous growth in the net debt to GDP ratio is displayed in Figure 2 A. The operational and primary deficit measures clearly show the fiscal stance deterioration after the first quarter of 1995. As explained earlier, the nominal deficit cannot be used to make any inference during the first year of the Real plan because it is still heavily contaminated by the previous very large inflation rates. It is only after October, $1998^{11}$ that the fiscal stance improves.

\section{FIGURE 2 A}

PSBR - Nominal, Primary and Operational Deficits (\% of GDP)

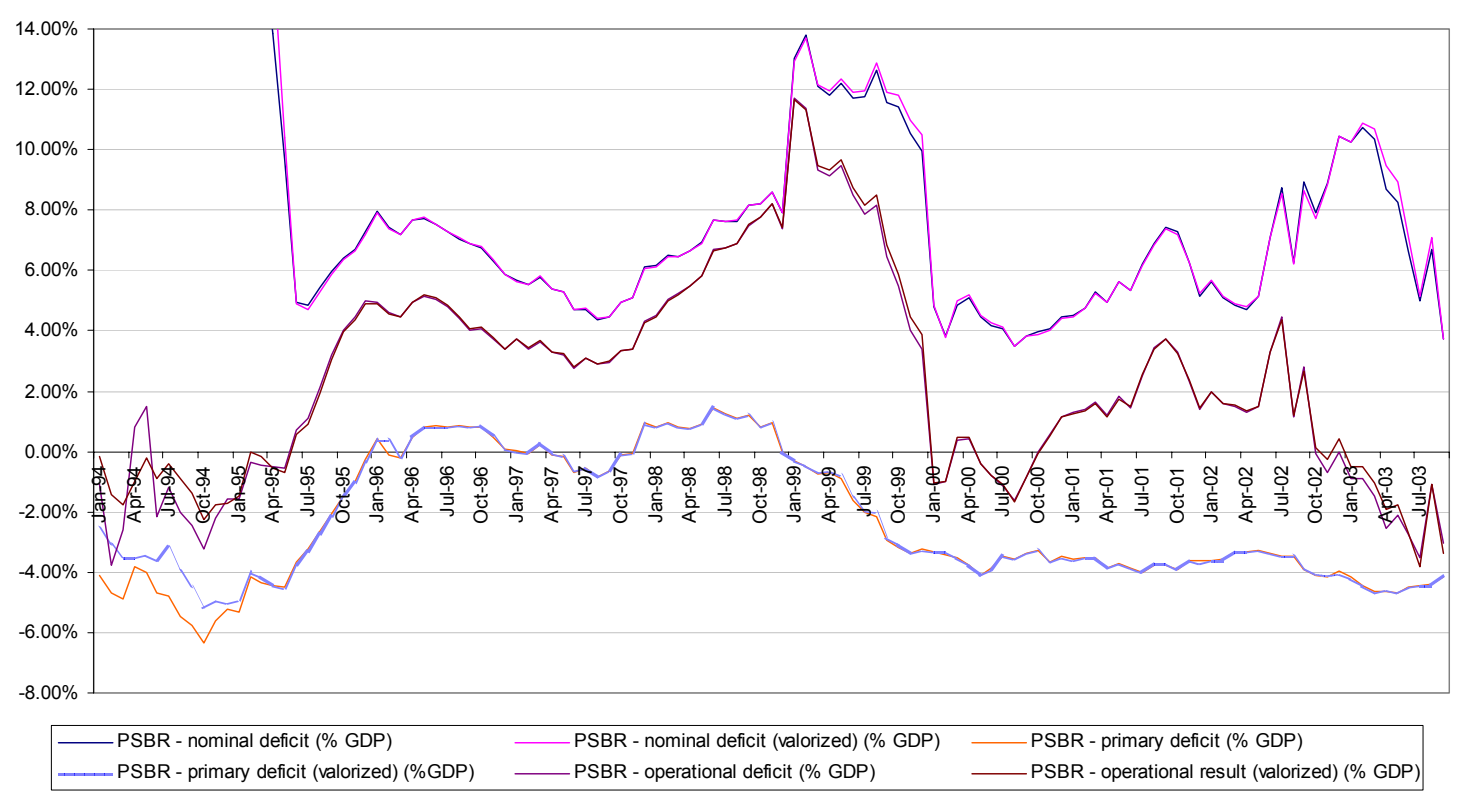

However bad during the period 1995-1998, the fiscal stance is not the sole responsible for the doubling of the net debt to GDP ratio. Many other factors influenced the behavior of the debt. Bevilaqua and Garcia (2001), analyzing the increase in the bonded public debt during the period 1995-2000, pointed out that extremely high interest payments were the main culprits of the debt explosion. ${ }^{12}$ It has been a matter of great discussion in Brazil how much of the high interest rates were endogenously determined by the weak fiscal stance. On one corner, the economists at Central Bank during the first term of President Fernando Henrique Cardoso argued that to keep inflation at bay they had to maintain a very high real interest rate given the weak fiscal stance. On the opposite corner, other economists argued that interest rates were kept that high only to maintain the (overvalued) exchange rate. One interpretation is that during good times (between the

11 Although correlation does not imply causation, the change in the fiscal stance was simultaneous to the agreement with the IMF.

12 Here, we use the primary deficit as a measure of the fiscal stance, according to the usual practice of successful stabilization programs (see Missale, Giavazzi and Benigno 2000). This is because the nominal (and, in lesser measure, real) interest payments are determined by many factors and may hinder the actual changes in the fiscal stance. 
Mexican crisis and the Asian crisis, and for a few months between the end of the Asian crisis and the start of the Russian crisis), interest rates were kept above what was required by covered interest parity to fight inflation. Figure $2 \mathrm{~B}$ displays the behavior of two measures of country (Brazil) risk, one constructed with external debt yield (C-Bond yield minus the yield of the T-bill of equivalent duration) and the other constructed with the domestic one-year interest rate (the covered interest parity differential) ${ }^{13}$ In those tranquil periods before the floatation of the real (January 1999), to avoid the inconsistent trinity, controls on capital inflows were put in place so that the restrictive monetary policy could be undertaken. ${ }^{14}$ In bad times, i.e., periods of high risk aversion in international financial markets, interest rates were raised even higher to avoid capital outflows which would kill the exchange-rate peg. In any case, it is only reasonable to assume that a tougher fiscal stance would have allowed a smaller real interest rate. On the other hand, had the peg ended before 1999, probably a lower real rate would have been paid during the intervening years. Therefore, when analyzing the debt decomposition exercises presented below, one has to bear in mind the stochastic relations between the variables, which lie at the heart of the simulation procedures presented in Section III.

FIGURE 2 B

Two Measures of Brazil Risk: Domestic and External Debt

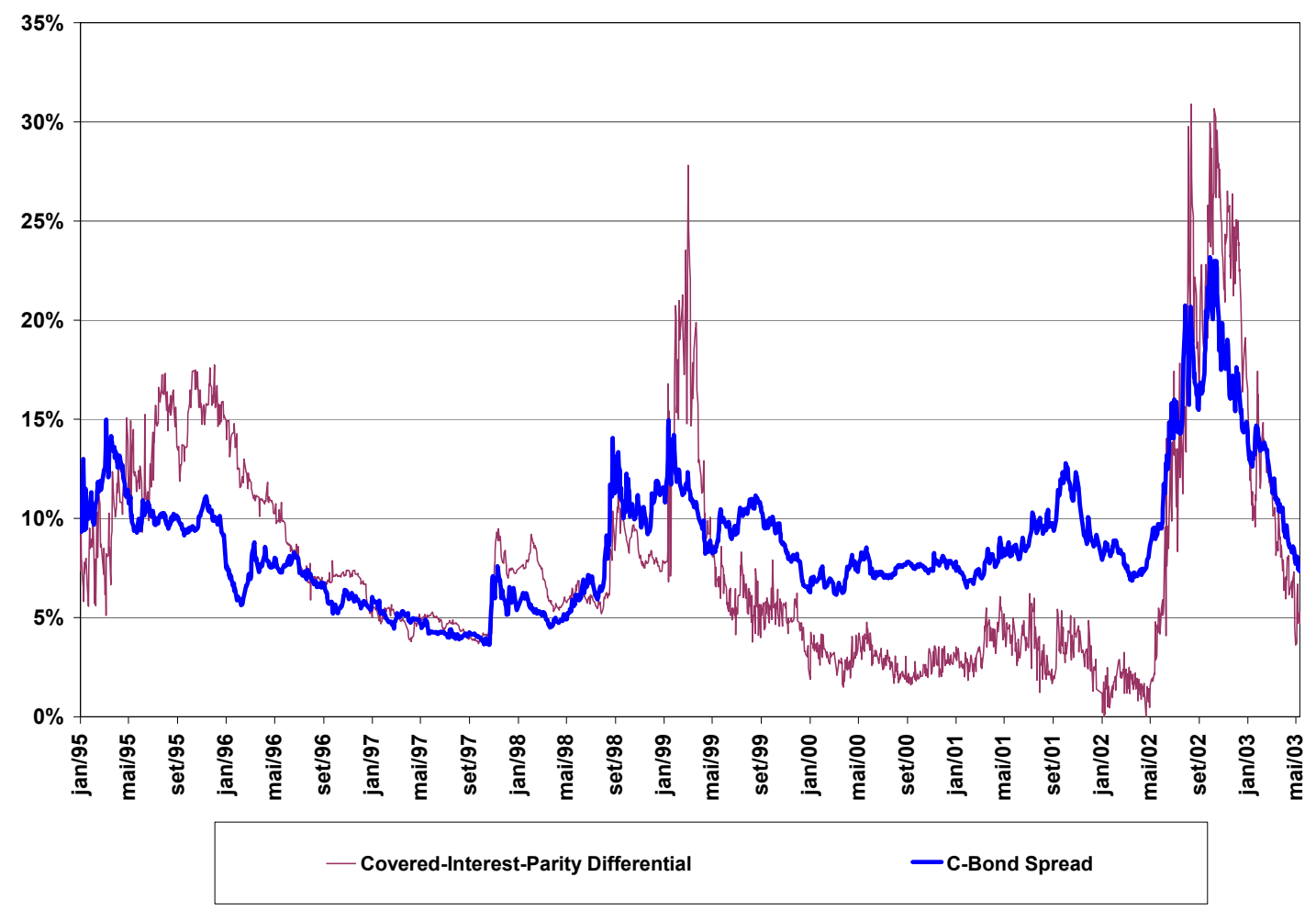

13 Note that there are many differences between the domestic and the external bond whose yields are used to compute the two country risk measures, among them the much longer duration of the C-Bond. Nevertheless, the regularity pointed out remains valid. For details, see Garcia and Didier (2003).

14 A description and an evaluation of the effectiveness of the capital controls on inflows is done in Garcia and Valpassos (2000). See also Cardoso and Goldfajn (1998). 
Besides high interest payments, the so-called skeletons (contingent liabilities that turned sour) contributed significantly to the debt increase. Figure 1 shows the evolution of a hypothetical debt to GDP ratio had the skeletons not existed. The net debt to GDP ratio would have fallen by more than 6 p.p. of GDP had the skeletons not existed. On the other hand, had the government not privatized, the debt would have increased. The net effect of both privatizations and skeletons is negligible, as displayed in Figure 1 by the series "Hypothetical Net Debt without Skeletons and Privatizations." Note that this a mere accounting exercise, not a counterfactual one. ${ }^{15}$

The effect of the devaluations can be seen in the series "Hypothetical Net Debt without Skeletons, Privatizations and Exchange-Rate Devaluations". Again, since this is not a counterfactual exercise, the series has a downward bias. This is because lower interest rates accrued on public bonds denominated or indexed in US\$ (vis-à-vis the non indexed ones) because of the forecasted devaluation and the currency risk. A flexible exchange rate regime would probably have required higher dollar rates, leading to higher net debt to GDP ratios along the counterfactual path. Despite these flaws, this series shows that the net debt to GDP ratio would hover around 37\% by August 2003 had skeletons and privatizations being out of the picture, and the nominal exchange rate remained ( $a$ la chinoise) at par with the US\$.

The simulation procedure of Section III, among several uses, may also be used to perform a complete counterfactual exercise. For example, given the structures of correlations estimated by the VAR, by hypothesizing a different path for the primary deficit, one would also change the (endogenously determined) interest rates, affecting the debt both directly (through the primary deficit) and indirectly (through the interest payments). ${ }^{16}$

15 For a counterfactual exercise, see Goldfajn and Guardia (2003).

16 We will perform such full-blown counterfactual exercises in a future version. 


\section{III.Risk Management Approach}

In this section we evaluate the debt sustainability question from a risk management perspective. Most of the debt sustainability literature concentrates on the debt accumulation equation

$$
d_{t}=\left(1+r_{t}-g_{t}\right) d_{t-1}+f_{t}
$$

where $d_{t}$ is the debt to GDP ratio, $r_{t}$ is the real interest rate paid, $g_{t}$ is the growth rate of GDP, and $f_{t}$ is the primary deficit. The idea in this equation is to determine the primary deficit or growth rate of GDP that would maintain the debt at certain level. This literature has been tremendously important in offering insights on the importance and timing of stabilization programs, as well as debt restructuring. ${ }^{17}$

In this paper we recognize that the variables entering this equation are stochastic, and perhaps, correlated. Furthermore, we also consider the possibility that there are other external variables (such as the exchange rate and inflation rate) that could generate comovement in the variables entering the debt accumulation equation. In particular, we assume that

$$
\begin{aligned}
& d_{t}=\left(1+\widetilde{r}_{t}-\widetilde{g}_{t}\right) d_{t-1}+\widetilde{f}_{t}+\widetilde{\varepsilon}_{t} \\
& \left\{\widetilde{r}_{t}, \widetilde{g}_{t}, \widetilde{f}_{t}, \widetilde{\varepsilon}_{t}, \widetilde{s}_{t}, \widetilde{\pi}_{t}\right\} \sim N\left(\vec{\mu}_{t}, \Sigma_{t}\right)
\end{aligned}
$$

where $\widetilde{r}_{t}, \widetilde{g}_{t}, \widetilde{f}_{t}, \widetilde{\varepsilon}_{t}, \widetilde{s}_{t}$, and $\widetilde{\pi}_{t}$ are the stochastic real interest rate, growth rate of GDP, primary deficit, debt shocks (skeletons $(+)$ and privatizations $(-)$ ), the real exchange rate, and the inflation rate. We also assume that they are distributed multinomial ${ }^{18}$ with conditional mean $\vec{\mu}_{t}$, and conditional covariance matrix $\Sigma_{t}$.

The risk management approach to debt sustainability is simply the characterization of the evolution of all the relevant stochastic variables and the calculation of the different debt paths. The idea is to estimate the conditional means and variances from the data and simulate the different paths of the debt - from those paths, we can compute the probability the debt will reach some level within some time and measure risk accordingly.

The properties of the covariance matrix are important to debt sustainability. For example, in developed economies recessions (lower growth) are usually accompanied by a

17 For a review of the possible criteria to determine debt sustainability, see Chapter III of the September, 2003 World Economic Outlook (IMF 2003).

18 We are assuming that the variables are normally distributed, even though some of them cannot be negative. This is a simplification that can be easily corrected in the Monte Carlo exercise. Here it is made mainly for expositional purposes. 
decrease in the interest rate (expansionary monetary policy). If this is the case, then the recession and the deterioration of the primary deficit - which are hurting the debt sustainability - comes with a reduction in the interest rate - which is helping debt sustainability. There is an automatic stabilizer in the equation. On the other hand, in emerging market economies, usually a recession deteriorates the fiscal accounts, increases the real interest rate, induces inflation and depreciates the exchange rate. If the sovereign debt is in dollars (which is usually the case), then all the variables are making the debt dynamics worse. Therefore, for emerging economies, the risk (covariance) part of debt sustainability becomes predominant, and simulations that postulate independent paths for the relevant variables badly miss this key feature.

\section{A. Methodology}

In this section we briefly discuss the procedure used to compute the debt dynamics. The variables considered are the following: real growth of GDP, real interest rate, the primary deficit measured as a share of GDP, the skeletons derived from the debt dynamics equation, the real exchange rate computed as the nominal depreciation minus inflation, and the inflation rate. All the data are monthly.

To compute the debt shocks, or skeletons, we take the actual debt data and realizations of the growth rate and interest rates and compute

$$
\widetilde{\varepsilon}_{t}=d_{t}-\left(1+\widetilde{r}_{t}-\widetilde{g}_{t}\right) d_{t-1}-\widetilde{f}_{t}
$$

We then compute a VAR using the macro variables. One problem that might arise from using a VAR is that if the variables are non-stationary but cointegrated we should run a error correction model. Unfortunately the data we have is extremely short, and there is little hope that the standard tests are strong enough to produce a definite answer. Because we know that even in near unit root setups VAR's produce consistent estimates (see Rothenberg and Stock (1997)) we decided to pursue this alternative. Therefore, the macrovariables are given by

$$
\begin{aligned}
& X_{t}=c+B(L) X_{t}+v_{t} \\
& X_{t} \equiv\left(\widetilde{r}_{t}, \widetilde{g}_{t}, \widetilde{f}_{t}, \widetilde{\varepsilon}_{t}, \widetilde{s}_{t}, \widetilde{\pi}_{t}\right) \\
& v_{t} \sim N(0, \Omega)
\end{aligned}
$$

where $v_{t}$ are the reduced form residuals distributed multinomial with mean zero and covariance matrix $\Omega$, and $B(L)$ are the coefficients of the lags. Using the Choleski decomposition of the reduced form residuals we generate several paths of the shocks and using the coefficients from the VAR we can compute the path of the variables in $X_{t}$ which can be used to estimate the path of the debt. 
This simple procedure uses Monte Carlo to determine several paths of the debt. It has several advantages: First, because we are not interested in estimating the contemporaneous causality between the macro variables, the VAR is used only to produce the best predictor on the joint dynamics of the macro variables. In other words, most applications on monetary policy are interested in computing impulse responses and identifying structural shocks from the reduced form. In this paper this is not our objective, although in Section III.D below we will compute some impulse responses. However, to understand the dynamics of the macro variables - or better said - to describe it, the only requirement is to produce the contemporaneous correlation as the result of some Choleski decomposition. Indeed, any Choleski decomposition (meaning any ordering of the variables in the VAR) will produce the same reduced form covariance matrix - which explains why for risk management applications the ordering is irrelevant. $^{19}$

Second, the procedure can be used to estimate rolling regressions - that will be used to assess the predictive power of the model and perform out of sample tests. This also allows us to estimate the model using the most recent conditions to compute different debt dynamics. Finally, this allows us to compare how different exchange rate regimes might impact the debt sustainability by concentrating only on the correlation structure.

Third, variables and shocks that are not part of the debt accumulation equation still can have an impact on the debt dynamics. For example, the exchange rate, the terms of trade, and inflation can be included as variables in the VAR and analyze their impact on the debt.

Finally, even if variables are not included, it is possible that the VAR could summarize their effect. For example, if terms of trade is not included but their impact on the debt dynamic is going to show up either as output, inflation or a real exchange rate depreciation, then the fact that it has been excluded from the VAR does not mean that its effect is not included - or summarized - in the variance covariance matrix of the reduced form residuals.

\section{B. Debt sustainability}

In this section we present the results from estimating the procedure described previously to the case of Brazil. There are several aspects that are important in the estimation - such as the choice of the relevant interest rate - that are discussed in detail. Furthermore, we studied the sensitivity of the results to changes in some of the assumptions.

The variables we included are: (i) total net debt; (ii) GDP and GDP growth - which were computed from the 12 months "valorized" GDP; (iii) the real interest rate was computed

19 The intuition is that the covariance matrix of the reduced form can have several triangular factorizations - which in the VAR language it means that they have different orderings. There are as many triangular factorizations as the factorial of the number of variables (or columns of the matrix), which corresponds to the number of different permutations of the variables. Each factorization recovers - by definition - the original matrix but implies different Choleski decompositions. 
as the Selic rate minus the inflation in the WPI; (iv) the primary deficit is the "valorized" deficit divided by the "valorized" GDP; (v) the real exchange rate change was computed as the change in the nominal Real - US Dollar exchange rate minus the inflation rate (WPI) $;^{20}$ (vi) and finally, the inflation rate used is the monthly WPI. ${ }^{21}$

The first step is to compute the skeletons and estimate the VAR using the six variables. The point estimates of the VAR are of little interest, so not shown here, the covariance of the reduced form residuals, on the other hand, deserves special attention.

Table 1

Covariance and correlation matrix

\begin{tabular}{|c|c|c|c|c|c|c|}
\hline & & & & \multicolumn{3}{|c|}{ Real } \\
\hline & Real & Real & & & Exchange & Nominal \\
\hline & Interest & Growth & Primary & Debt & Rate & Inflation \\
\hline & Rate & Rate & Deficit & Shocks & Depreciation & (WPI) \\
\hline Real Interest Rate & 1.9249 & 0.5218 & 0.4930 & -0.8032 & -0.1197 & 4.4742 \\
\hline Real Growth Rate & $35.2 \%$ & 1.1388 & 0.3883 & -0.1694 & 2.6442 & -2.2608 \\
\hline Primary Deficit & $17.8 \%$ & $18.2 \%$ & 3.9911 & -3.5271 & 1.6101 & -1.9419 \\
\hline Debt Shocks & $-25.5 \%$ & $-7.0 \%$ & $-77.7 \%$ & 5.1605 & -1.6374 & -0.8513 \\
\hline Real Exchange Rate Depreciation & $-1.0 \%$ & $28.6 \%$ & $9.3 \%$ & $-8.3 \%$ & 74.8589 & -14.2580 \\
\hline Nominal Inflation (WPI) & $34.8 \%$ & $-22.8 \%$ & $-10.5 \%$ & $-4.0 \%$ & $-17.8 \%$ & 86.0028 \\
\hline
\end{tabular}

In Table 1, we show the covariance matrix of the reduced form residuals on the upper triangular, and on the lower triangular we show the correlations (highlighted). Some patterns of correlation are worth emphasizing. First, the primary deficit is positively associated with the real interest rate and the growth rate. These correlations are compatible with the standard Keynesian fiscal multiplier effects. Second, the inflation rate is positively correlated with the real interest rate, and negatively correlated with the growth rate. As we mentioned before, in emerging markets it is common that inflation scares are recessionary and increase the real interest rates. Furthermore, notice that the inflation rate is negatively correlated with the real exchange rate but the pass through is less than one to one given that the correlation is quite small. Third, a real exchange rate depreciation is associated with an increase in the fiscal deficit (the correlation is small but positive), but an increase in growth. Remember that these correlations reflect partial correlations and therefore in this discussion, the real exchange rate depreciation is assumed to have happened without inflation. In other words, this is a true real exchange rate depreciation and therefore expansionary in terms of output. On the other hand, most of the actual depreciations we observe in Brazil are accompanied by both the change in the real exchange rate and an increase in the inflation rate. In this case, the first movement increases output, while the second one would reduce it. The final effect has to be computed by looking at impulse responses. See Section III.D below.

20 Since the US inflation has very low variance in the sample, we exclude it from the real exchange rate calculation. In our framework, the constant term in the regression takes care of the effect of the US inflation on the real exchange rate.

$21 \quad$ We also computed the model using the CPI and no difference on the main message was found. 
Before concentrating on impulse responses, which are sensitive to the ordering of the variables in the VAR, we study the implications of the correlation structure on the debt. To compute the debt path we need to determine the initial conditions, i.e. what is the initial primary deficit, interest rate, growth rate, etc? To simplify the analysis we have decided to use the average of these variables the previous 9 months. We estimated the same path using only 6 months, and extending to 12 and 24 months. The results are almost unaltered by this assumption - hence we use 9 months to determine the initial conditions and all the data available up to that point to estimate the VAR and the covariance matrix..

In Figure 3, we present the debt path using the initial conditions computed at the end of September of 2002. In other words, we compute the debt accumulation equation using the inflation rate, interest rate, primary deficit, growth rate of the previous 9 months, and the final debt, the path of future debt assuming those variables remain constant is depicted in Figure 3. This is the path for the following 30 months.

Figure 3

Debt sustainability in the absence of risk

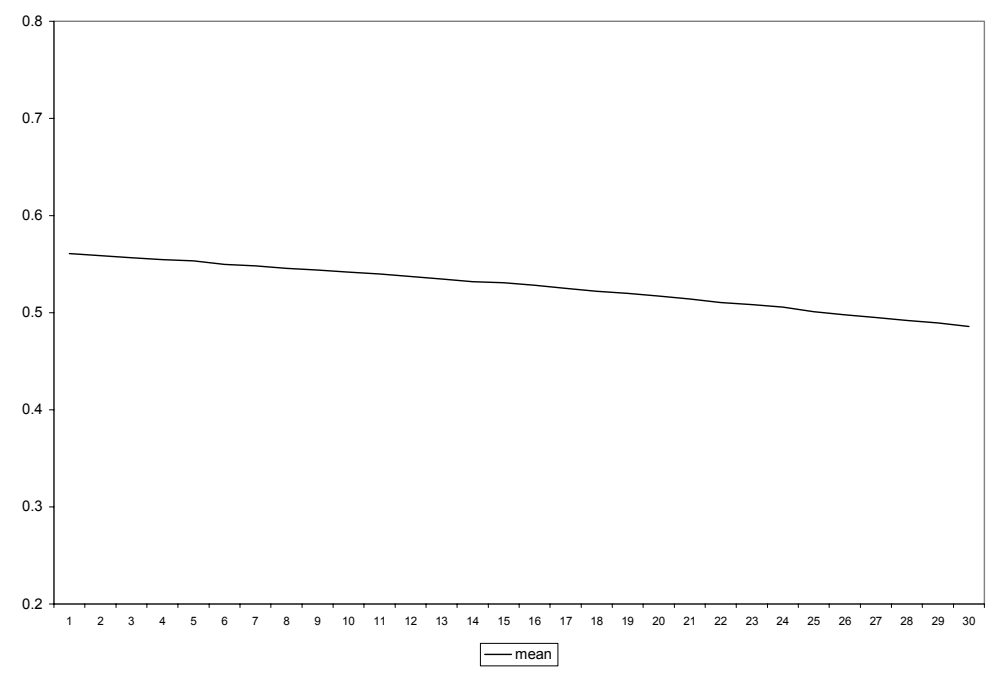

Notice that starting from almost 60 percent debt, the debt would gradually fall to just above 50 percent of GDP 30 months hence. It is possible to conclude from this exercise that the debt in Brazil given the value of the current macroeconomic variables is sustainable. However, this would be the wrong conclusion. Indeed, we perform the Monte Carlo exercise and show in Figure 4 the path of the debt, the maximum and minimum debt, the 95 and 5 percent bands, and the standard deviation of the debt to GDP ratio are shown. 
Figure 4

Debt sustainability with risk.

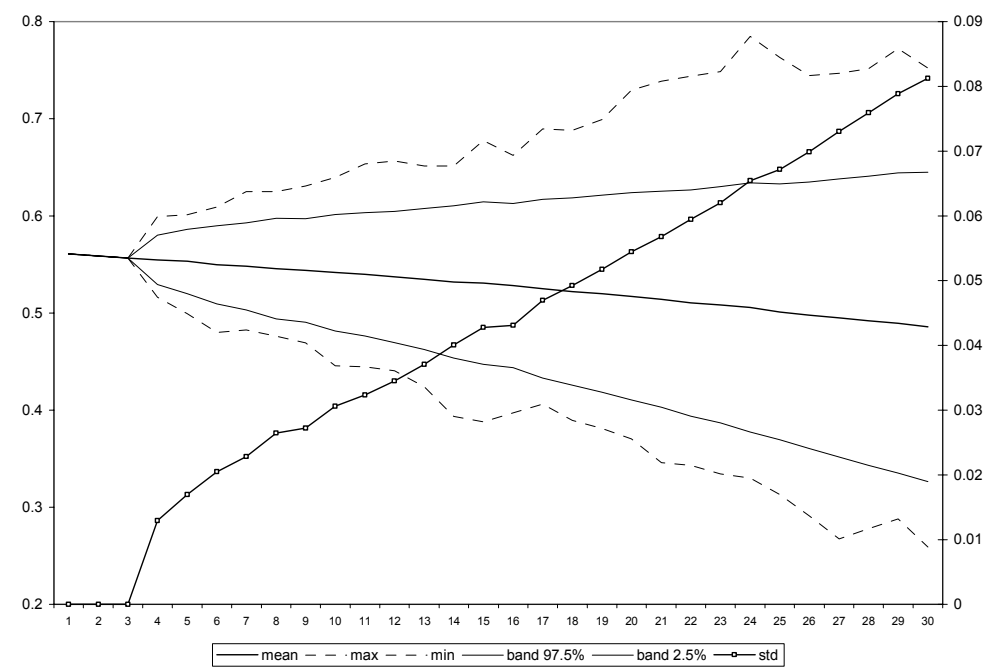

The standard deviation of the debt to GDP ratio is measured in the right hand side scale, while all the other variables are measured on the left hand. ${ }^{22}$

There are several important points that can be extracted from Figures 3 and 4 . First, it is the case that the debt on average is falling, as the standard debt sustainability exercise would imply. Second, there is a non-trivial proportion of realizations in which the debt increases to more than 70 percent - a level of debt that would be considered extremely large for an emerging market. ${ }^{23}$ Remember that the horizon of study is only two and a half years and the debt to GDP reaching 80 percent in that period reflects a very fast accumulation when we consider we are starting from less than 60 percent and the means of the stochastic variables is pointing to a debt reduction. Third, the volatility of the debt to GDP ratio is increasing through time. It is easy to show that the debt to GDP ratio has a variance that is increasing faster than the one implied from a random walk. In other words, the variance $\mathrm{T}$ periods ahead is larger than $\mathrm{T}$ times the variance of one period ahead. In other words, the variance is increasing not only because simulation period is longer, but because the covariance matrix is such that the opposite of a diversification effect arises. This is the opposite of the automatic stabilizer effect that exists in developed economies, as mentioned earlier.

In Figure 5 we present the standard deviation of the debt adjusted by the horizon. Here we present the simulations for the next 4 years. As can be seen, after one year, the volatility increases more than proportionally to time. This is the result found in several of the simulations; the real interest rate in some of them is larger than the growth rate of output generating an exploding debt path.

22 The shocks are zero the first two periods because the VAR was estimated using 2 lags.

See Reinhart, Rogoff and Savastano (2003). 
Figure 5

Adjusted Variance by Horizon.

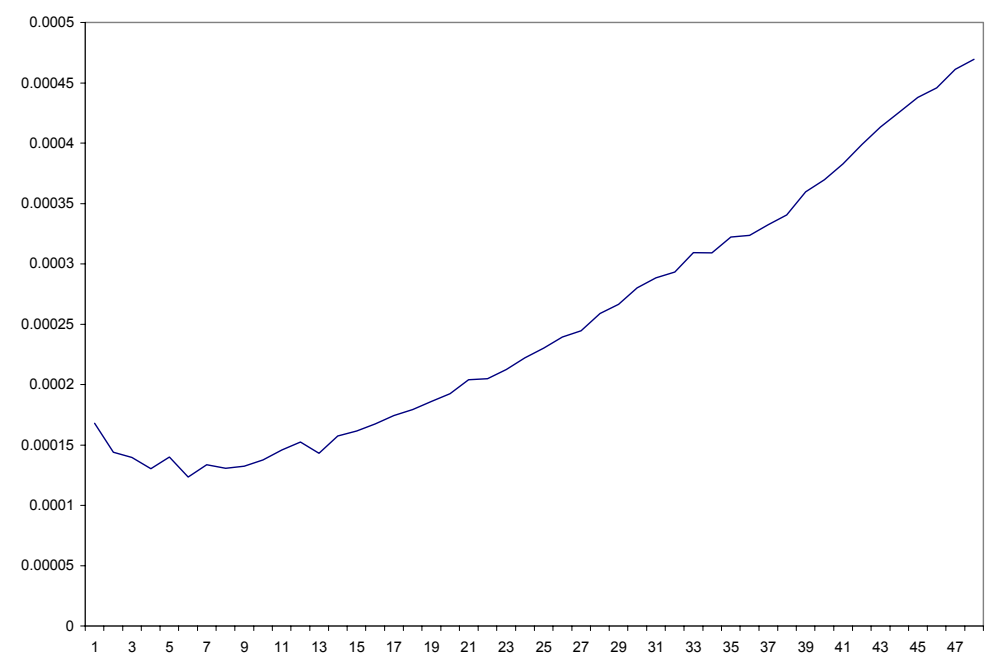

\section{Debt sustainability and sovereign spreads}

In the previous section we studied the properties of the debt 30 months after the current situation. In this section, we repeat this exercise for each month starting in January of 2001. The idea is to compute the VAR with the available data up to month $t$, and compute the path of the debt afterwards for 10 years. Using those paths we can compute an statistic on the debt - lets say the probability that the debt to GDP ratio is larger than 75 percent. Then we can repeat the exercise for month $t+1$. This rolling exercise produces a path for several statistics of the debt.

In Figure 6 we present the results for the probabilities of reaching a debt larger than 66, $75,85,95$ and 100 percent of GDP in the following 10 years. The interpretation of this is the following. For example, assume that we are estimating these probabilities for June of 2002. Using all the data until May of 2002 we estimate the VAR, the covariance matrix of the shocks, and generate the Monte Carlo simulations (500 replications of 120 months). With the simulated paths we compute the debt for each of them using the debt accumulation equation and the estimates from the VAR. Then we compute the number of times the debt reaches some threshold (say, 75 percent of GDP) in any month of the next 10 years. Hence, for June of 2002, given the initial conditions at that time, the real interest rate and the covariance matrix estimated until the previous month, the probability of a debt to GDP ratio larger than 75 percent is 79 percent, while it has a 59 percent chance of being larger than 100 percent of GDP. In other words, at that time it is clear that the situation existing in Brazil implies a very risky path of the debt. In other times, such as in May or June of 2003, these probabilities are much smaller. The exercise performed here is akin to a stress test. 
Figure 6

Probability of debt to GDP ratio reaching more than threshold in following ten years.

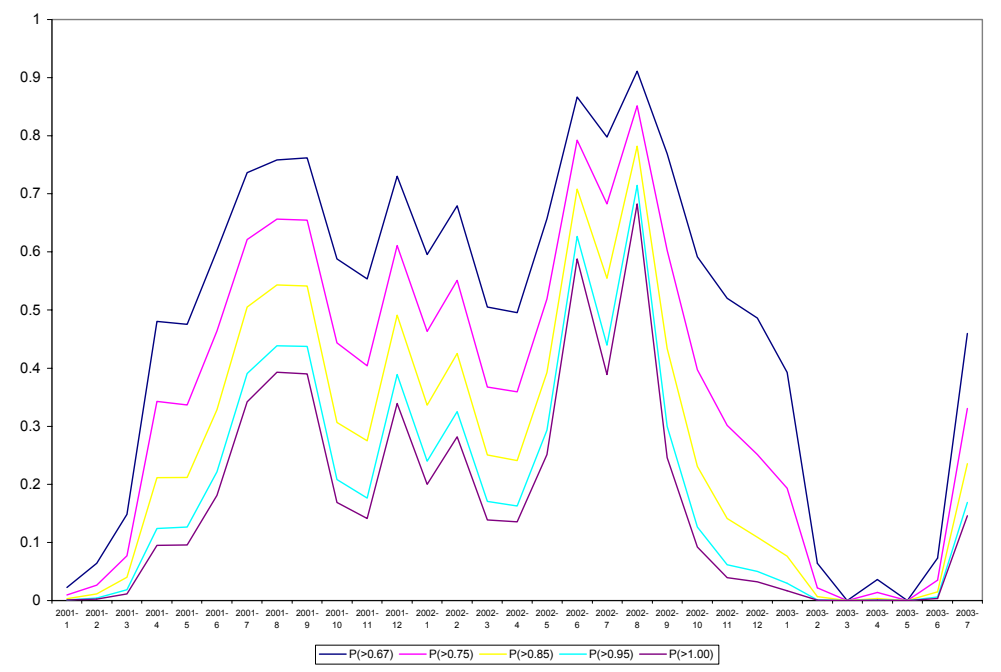

It is important to mention that in order to construct these paths we are using only information from the past. Hence this is an out-of-sample exercise. The idea is to compare one of these paths with the the EMBI+ yield. Figure 7 shows the results.

Figure 7

Probability of total debt to be larger than 75 percent of GDP at any time in the following 10 years, and the EMBI+ spread

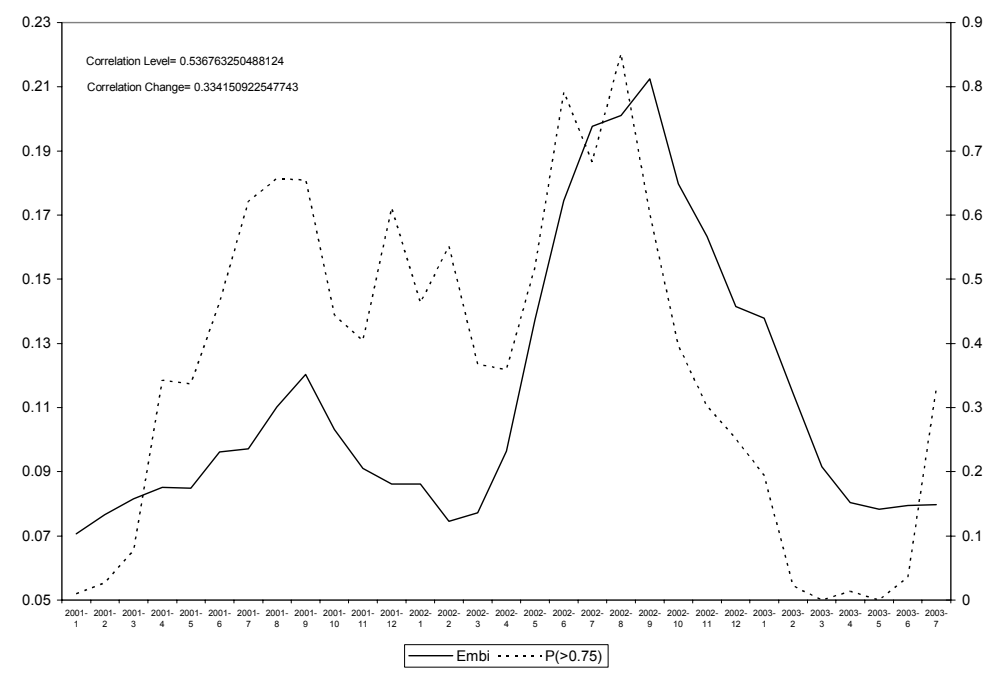

As can be seen in Figure 7, the probability and the spread on the EMBI are closely related. First, our procedure is out-of-sample in the sense that to compute the probability in month $t$, we use only information until time $t-1$, and we compare the probability with the average interest rate on the EMBI on month $t$. 
The correlation between these two series is 54 percent on levels and 33 percent in changes.

A simple regression analysis shows that our variable has strong predictive power on the future EMBI+ spreads. A simple AR(2) model produces

$$
\Delta s_{t}=\underset{1.58}{0.3155 \Delta s_{t-1}}+\underset{0.54}{0.0970 \Delta s_{t-2}}+\underset{2.14}{0.0354} p_{t-1}+\underset{2.28}{0.0428} p_{t-2}
$$

where $\Delta s_{t}$ is the change in the EMBI+ spread, and $p_{t}$ is the probability that the debt reaches some threshold in our Monte Carlo exercises. As can be seen the probabilities are significant - even though they have been computed with data before the month where the change in the EMBI is taking place. The $\mathrm{R}$ square of the regression is economically important: 56 percent. In fact, the AR(2) without the probability measures has only one of coefficient significant $\left(\Delta s_{t-1}\right)$ and an R square of 38 percent. Indeed, the simple $\mathrm{F}$ tests show that the $\mathrm{p}$-value of the significance of the lagged changes in the EMBI+ spread is 8.9 percent $(\mathrm{H} 0$ : the coefficients on the two lagged changes in the EMBI+ spread are zero), and 2.2 percent for the probabilities lags (H0: the coefficients on the two lagged probabilities are zero).

We interpret these results as a strong corroboration that our methodology captures the bulk of market perception of the default risk in Brazilian sovereign debt, and that such risk measure is largely correlated with the Brazilian risk spread. We therefore think that theses probabilities constitute an alternative, very effective, method to assess debt sustainability.

\section{Impulse responses}

One of the advantages of the previous procedure evaluating the path of the debt is that we do not have to commit ourselves to a particular structural model or distribution of the residuals. This is crucial in countries such as Brazil because the standard triangular assumption imposed in monetary economy is rarely satisfied. It is hardly the case that decisions of monetary policy in a particular month do not affect prices, output, or exchange rates contemporaneously.

The previous analysis, by concentrating on the contemporaneous covariance of the residuals, allows us to study the path of the debt to the typical mixture of shocks that have hit the Brazilian economy. The only property imposed is that they have to satisfy the covariance matrix computed in the sample.

However, looking at the mixture of shocks does not always provide the best description. For example questions such as what is the impact of a depreciation of the exchange rate on the path of the debt cannot be answered. In this section, we will impose a triangular decomposition of the reduced form shocks, even though we believe that it may be a poor description of what really takes place in the Brazilian economy. Nevertheless, this 
exercise will provide some intuition about the behavior of the debt, but it is always subject to the critique that it depends crucially on the identification assumptions. This is an important limitation but unfortunately this is the best we can do with the available data.

In particular, we will assume that the ordering of the equations is as follows: real interest rate, GDP growth rate, primary fiscal deficit, skeletons, real exchange rate, and inflation. This order implies that inflation affects all the variables contemporaneously, while the real interest rate only acts with a lag.

Figure 8.1

Impulse response to an increase in the interest rate.

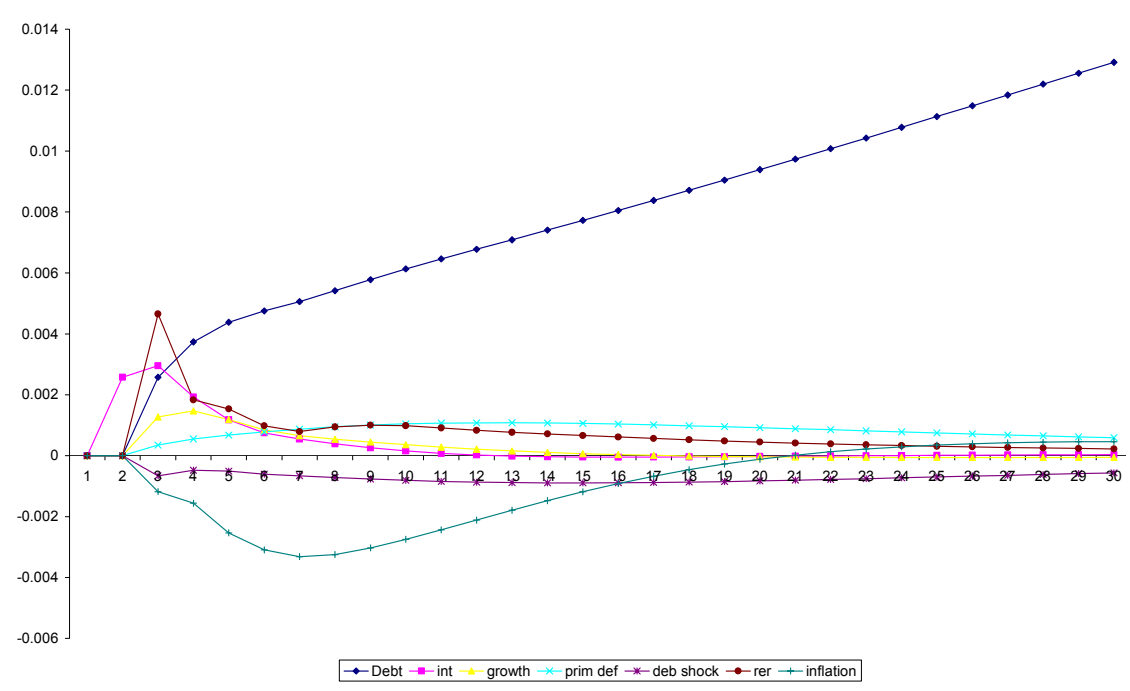

In Figure 8.1 to 8.6 we present the impulse responses of all the shocks plus the implied debt accumulation. The impulse response of each of the shocks is computed using the Choleski decomposition and the estimates from the VAR. The impulse response of the debt accumulation is calculated using the response of each of the shocks, the initial conditions at the end of the sample, and the debt accumulation equation.

In Figure 8.1 the impulse response to a one standard deviation increase in the real interest rate is depicted. As can be seen, the increase in the real interest rate is quite persistent and it lasts around 10 months. Notice that the increase in the real interest rate depreciates the real exchange rate and reduces the inflation rate. It has a small impact on the growth rate and the primary deficit. The net effect on the debt path is that an increase in the real interest rate increases the debt to GDP ratio, and according to our simulation and the given initial conditions, the debt keeps on growing for a long period of time even after the variables have returned to steady state. 
Figure 8.2

Impulse response to an increase in the growth rate of monthly output.

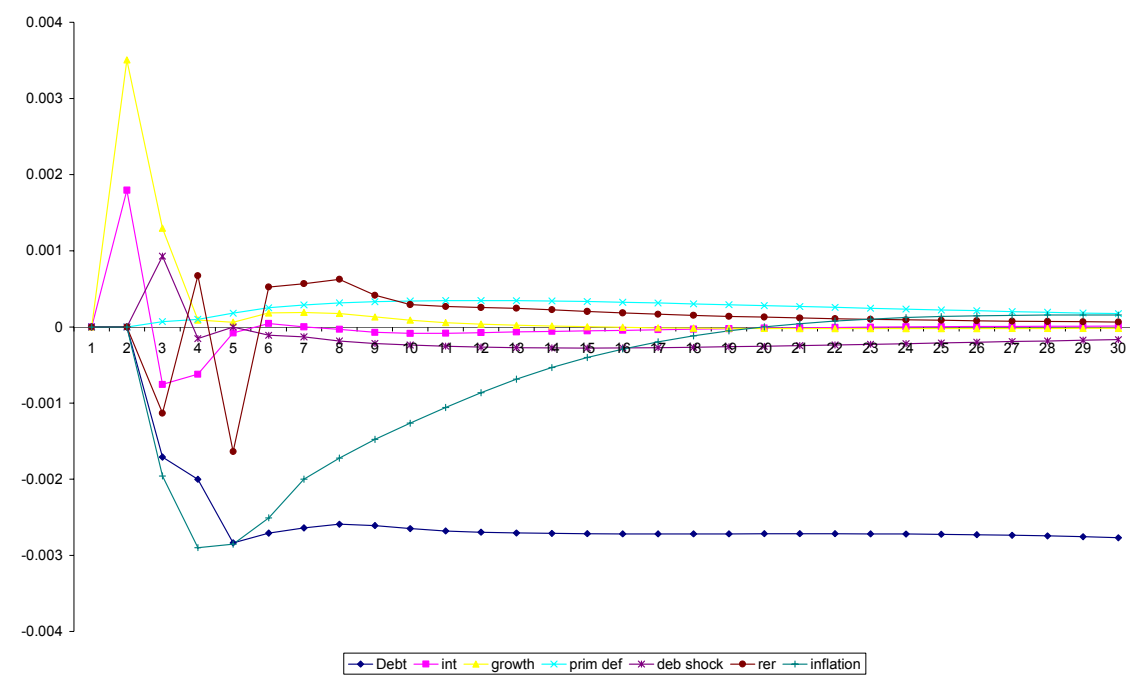

In Figure 8.2, the impulse response to a one standard deviation increase on the growth rate of output is depicted. As can be seen, the increase in the growth rate is associated with a contemporaneous increase in the real interest rate but subsequent reductions, a reduction in inflation rate, and a small real exchange rate appreciation.

In the end, the path of the debt reflects a permanent improvement. Notice that even when the variables are close to the steady state, the debt is almost constant at a lower level. One surprising result, at least to us, is the fact that the primary deficit is almost unaffected by the output increase. It is possible that this is the result of the bad identification, but also it could reflect that in the sample output increases are associated with expansionary fiscal policy.

Figure 8.3 looks at the impulse response after an increase in the primary deficit. In this case, the increase in the primary deficit is associated with a depreciation of the real exchange rate, an increase in the inflation rate, an increase in the interest rate, and a transitory increase in the growth rate. The shock and the first three reactions should deteriorate the debt to GDP ratio, but the increase in growth should improve it. In the end, our simulations show that the negative effects out-weight the positive ones and the debt to GDP ratio increases. In fact, in comparison to the previous two shocks, clearly the innovations to the primary deficit have the largest impact.

These three impulse responses confirm quite well our intuition about the impact of these shocks on the path of the debt. We should expect that increases in the real interest rate and deteriorations of the primary deficit tend to increase the debt, while increases in the growth rate tend to improve it. It is not appropriate to judge the identification of shocks by their impulse responses, but at least the results are not contradicting it. 
Figure 8.3

Impulse response to an increase in the primary deficit.

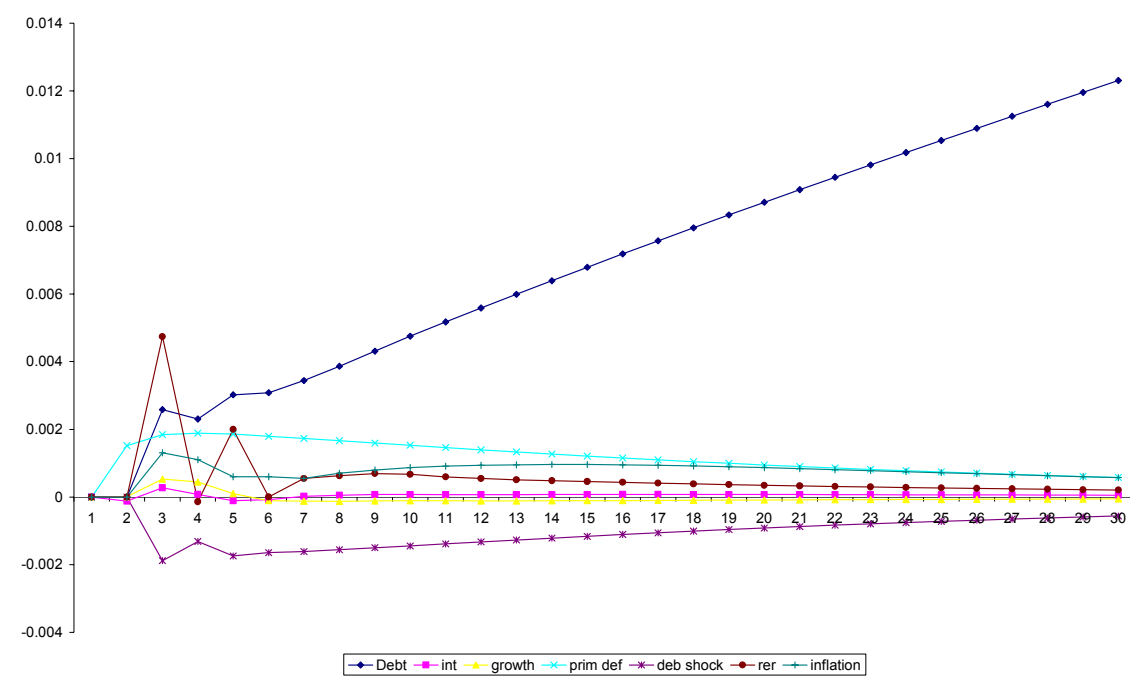

Figure 8.4

Impulse response to an increase in the skeletons.

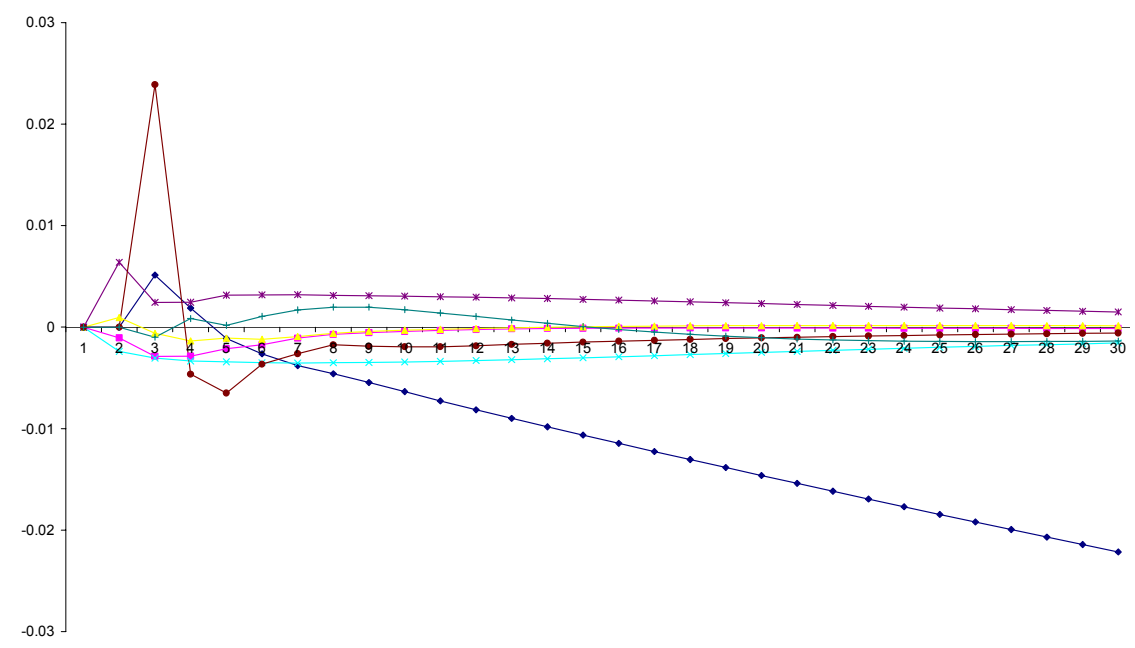

$\rightarrow-$ Debt $\rightarrow$-int $\rightarrow$ growth $\rightarrow$ - prim def $*$-deb shock $\rightarrow$-rer $\rightarrow$-inflation

In Figure 8.4 we study the impact of an increase in the skeletons. Our simulations show that there is a transitory increase in the debt to GDP ratio followed by a decline. This impulse response is hard to reconcile with intuition. Indeed, from all our responses this is the most inconsistent one.

In Figure 8.5 we depicted the impulse response to a real exchange rate depreciation. Before drawing any conclusions is important to remember that given our identification 
assumption this is a very particular form of depreciation. This is an exchange rate depreciation that is not accompanied by an increase in the inflation rate. In other words, this is a true real exchange rate depreciation. Increases in inflation rate, that could also cause a depreciation of the real exchange rate is the next shock. In other words, we can think of this shocks as the good part of the depreciation, and the next shocks as the bad part.

Figure 8.5

Impulse response to an increase in the real exchange rate (depreciation).

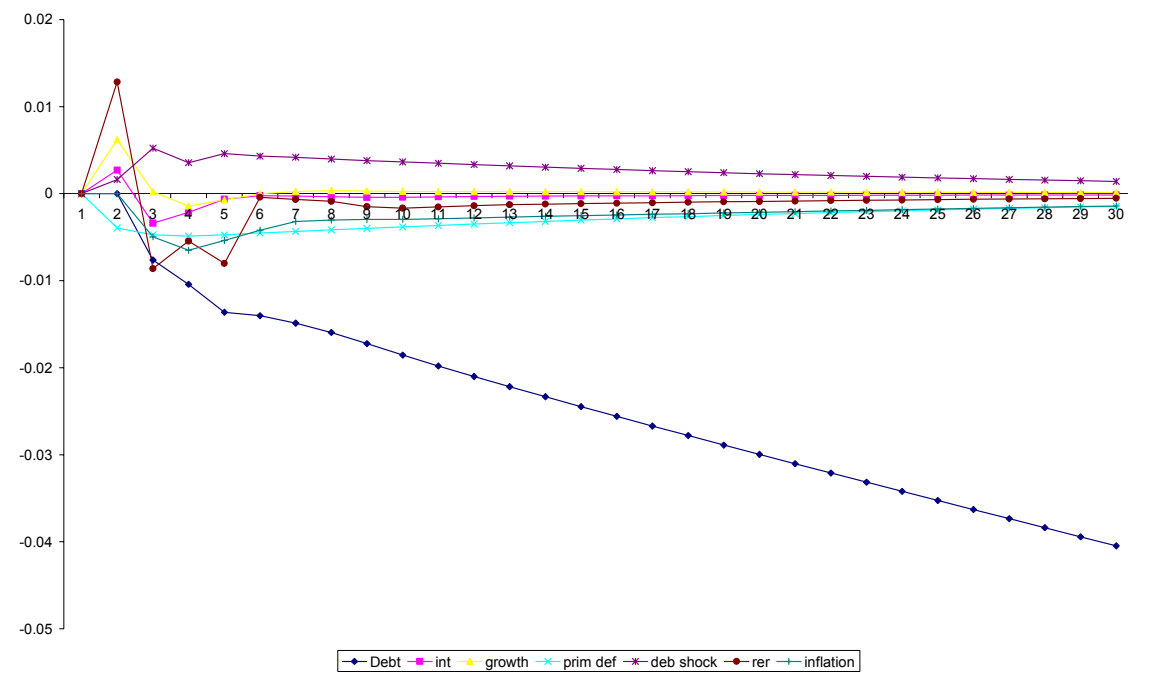

Notice that - in line with our "good" depreciation interpretation - an increase in the real exchange rate is accompanied by an increase in the growth rate, a moderate increase in the interest rate (smaller than the growth rate), and a large improvement in the primary deficit. This is exactly the implications of a real depreciation rate that is expansionary.

Because the increase in the growth rate is higher than the increase in the real interest rate in the end the debt to GDP ratio improves permanently.

The final exercise is shown in Figure 8.6. In this case we study the impulse response to an increase in the inflation rate. Given the identification assumption it is possible to interpret this shock as a nominal shock that depreciates the exchange rate and increases the inflation rate at the same time. Indeed, in the impulse response it can be seen that the increase in inflation also depreciates the real exchange rate very significantly. Furthermore, the real interest rate increases on impact while the growth rate declines, and the primary deficit deteriorates. The movement of all the variables points out to a clear increase in the debt to GDP ratio, which in fact takes place. 
It is important to remember that comparing the previous impulse responses the increase in the primary deficit and the increase in the inflation rate are the two most important ones - quantitatively speaking.

Figure 8.6

Impulse response to an increase in the inflation rate.

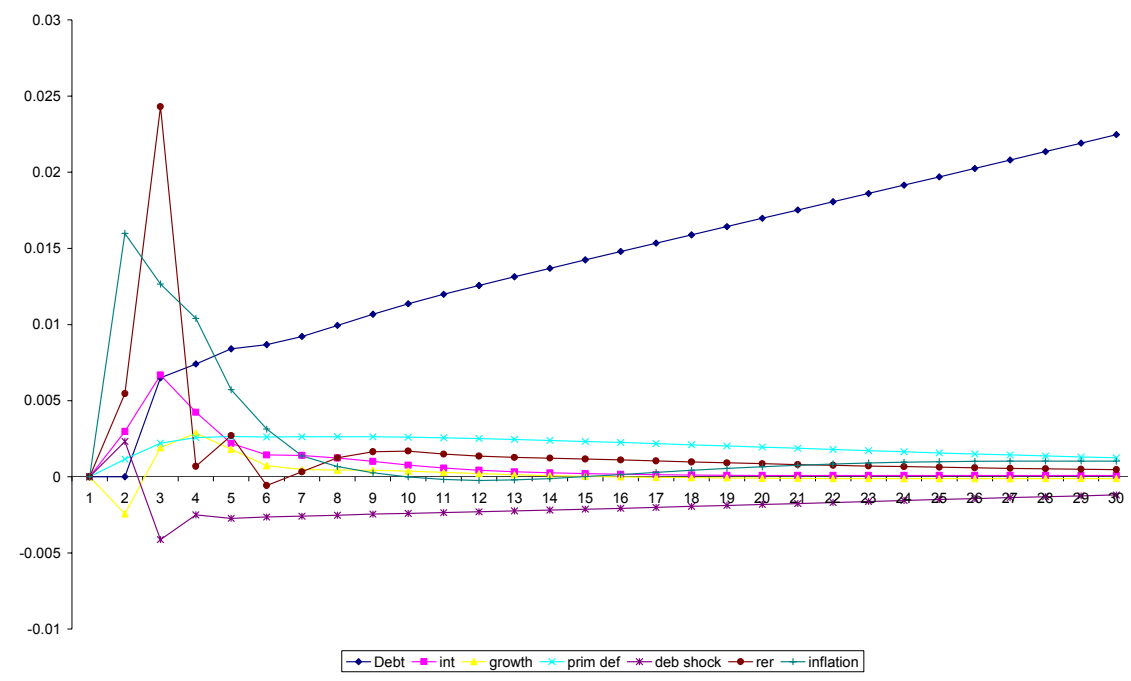

In this section we have made a big deal about the impulse responses and how the impact the path of the debt. It is important to reiterate what was mentioned in the introduction. The results in this section depend - crucially - on identification assumptions that are unlikely to be true in the data. With this caveat in mind, we still believe that something can be learned from the exercise. First, the comovement observed in the variables of interest and the debt dynamics are close to what our intuition would have predicted ${ }^{24}$ which is reassuring. Second, the magnitudes involved show that the most important shocks regarding the sensitivity of the debt to GDP ratio to the shock are innovations to the primary deficit and the inflation rate, where we have interpreted the innovations of the inflation rate as nominal shocks or "bad" exchange rate depreciations.

\section{Conclusions}

The main contribution of this paper is to propose a risk based measure to assess debt sustainability. The main insight that lead to this measure is that debt in emerging market economies is quite risky. An increasingly larger number of models and body of empirical evidence show that emerging market economies lack the natural stabilizing features that allow and make countercyclical policies effective. For example, during a recession, real interest rates tend to fall in developed economies, which makes room for larger primary

${ }^{24}$ Except for the skeletons. 
expenditures given the reduction in interest payments. In emerging market economies, often the reverse happens: real interest rate rises, government revenues fall and government outlays increase, thereby negatively leveraging the debt impact.

The proposed measure is constructed from a framework that combines a statistical model to uncover the stochastic relations among the variables that directly or indirectly influence the debt accumulation with a simulation engine that computes future paths for the debt to GDP ratios. The Monte Carlo simulations allow us to compute "risk probabilities", i.e., probabilities that the simulated Debt to GDP ratio exceeds a given threshold deemed risky (say, 75\% of GDP). The time-series of such probabilities is then used to investigate whether or not it is correlated with the market risk assessment, measured by the spread on sovereign dollar denominated debt.

The application of our methodology for Brazil shows that even though the debt could be sustainable in the absence of risk, there are many paths in which it is clearly unsustainable. I.e., although "on average" the Brazilian debt is sustainable, the correlation structure under which the Brazilian economy operates poses a huge question mark on the debt sustainability.

We also show that properties of the debt dynamics are closely related to the EMBI+ Brazil spread. This is quite a remarkable result, since our methodology uses out-ofsample simulations, and does not use regressors related to the risk aversion of international investors, as the high-yield spread in the US, which are deemed very important in the determination of the EMBI+ spread. Thus, our measures constitute an alternative, very effective, method to assess debt sustainability.

\section{References}

Bevilaqua, A. and M. Garcia. "Debt Management in Brazil: Evaluation of the Real Plan and Challenges Ahead," International Journal of Finance and Economics, January 2002.

Cardoso, E. and I. Goldfajn, "Capital Flows to Brazil -The Endogeneity of Capital Controls", IMF Staff Papers, v. 45, n.1, 1998 (also as IMF Working Paper, 97/115, 1997).

Garcia, M. "PUBLIC DEBT MANAGEMENT, MONETARY POLICY AND FINANCIAL INSTITUTIONS ", PUC-Rio working paper, July 2002.

Garcia, M. and T. Didier, "Very High Interest Rates and the Cousin Risks: Brazil During the Real Plan" in José González and Anne O. Krueger, eds., Macroeconomic Reforms: The Second Generation, The University of Chicago Press, 2003.

Garcia, M. and M. Valpassos,, "Capital Flows, Capital Controls and Currency Crisis: The Case of Brazil in the Nineties" in Felipe Larrain, ed., Capital Flows, Capital Controls, and Currency Crises: Latin America in the 1990s, University of Michigan Press, 2000.

Goldfajn, I.and E . Guardia, Fiscal Rules and Debt Sustainability in Brazil, forthcoming in a book edited by Kopvitz, George, IMF, 2003 (available at http://www.bcb.gov.br/pec/notastecnicas/ingl/2003nt39RegraFiscSustentDivBrasili.pdf). 
IMF, World Economic Outlook, September 2003.

Missale, A., F. Giavazzi and P. Benigno. "How is Debt Managed: Learning from Fiscal Stabilizations", RePEc:igi:igierp:174, September 2000.

Reinhart, C., K. Rogoff and M. Savastano. “Debt Intolerance,” Brookings Papers on Economic Activity, 2003.

Rothenberg, T. and J. Stock. "Inference in a Nearly Integrated Autoregressive Model with Nonnormal Innovations," Journal of Econometrics, 80 (1997), 269-286 